\title{
DHSS waiting list statistics—a major deception?
}

\author{
P A SYKES
}

It has been suggested recently that the Department of Health and Social Security's instructions for collecting National Health Service waiting list statistics in England and Wales ${ }^{1}$ contain anomalies as a result of the exclusion of several categories of patients awaiting surgery. ${ }^{2}$ The aim of this study was to quantify the anomalies in one district general hospital and to assess their effect in different surgical specialties.

\section{Method}

The DHSS instructs its staff on form SBH 203 to exclude various categories of patients when collecting information on waiting list statistics. The excluded groups include day cases, patients who wish to defer admission for personal reasons, including patients who have already failed to accept an offered date for admission, and patients who do not require admission until a later date for medical reasons. The number of patients in these excluded categories was identified in each surgical specialty in one district general hospital at a particular time.

In addition, the actual number of patients admitted under the care of one general surgeon in a three month period was studied and the number of bed days resulting from elective admissions and emergency admissions in this period was recorded.

\section{Results}

Details of all 1094 patients awaiting admission under the care of 10 surgeons are presented. Three of the surgeons were general surgeons, two were otolaryngologists, two were gynaecologists, two were orthopaedic surgeons, and one was a genitourinary surgeon.

The length of time that each patient had been on the waiting list and the proportion of patients who had failed to accept an offered date for admission are recorded in table I. Altogether 314 patients $(28 \cdot 7 \%)$ had already been offered admission but had declined for medical or social reasons.

Table II shows the expected inpatient stay for each patient, including day cases, on the waiting list according to specialty. This was estimated by a consultant surgeon with knowledge of the medical condition necessitating admission. The significance of the day cases varied greatly between specialties. For gynaecology none of 104 patients on the waiting list was planned as a day case, compared with 125 planned day cases from a total of 228 patients awaiting genitourinary surgery (55\%).

Another group excluded from the DHSS waiting list statistics are patients whose admission has been deferred until a later date for medical reasons-for example, patients required to lose weight before surgery or patients needing review after tumour surgery. Of

Park Hospital, Manchester M31 3SL

P A SYKES, MD, FRCS, consultant surgeon

Correspondence to: Park Hospital, Moorside Road, Davyhulme, Manchester M31 3SL. these patients, 46 (out of 218) were general surgical patients and 16.8 (of 228) urological patients. This contrasts with patients on the earô nose, and throat, orthopaedic, and gynaecological waiting list, none of whom fell in the "deferred" category (table III). Thus in TABLE I-Patients who failed to attend when
offered admission

\begin{tabular}{lcc}
\hline $\begin{array}{l}\text { Time on waiting } \\
\text { list } \\
\text { (months) }\end{array}$ & No of patients & $\begin{array}{c}\text { Patients } \\
\text { who failed } \\
\text { to attend }\end{array}$ \\
\hline $0-3$ & 450 & 59 \\
$3-6$ & 204 & 39 \\
$6-12$ & 230 & 58 \\
$12-24$ & 134 & 85 \\
Over 24 & 76 & 73 \\
\hline Total & 1094 & 314 \\
\hline
\end{tabular}

TABLE II-Expected inpatient stay in days

\begin{tabular}{|c|c|c|c|c|c|c|}
\hline \multirow[b]{2}{*}{ Specialty } & \multicolumn{5}{|c|}{ Length of stay (days) } & \multirow{2}{*}{$\begin{array}{c}\text { Total No } \\
\text { of } \\
\text { patients }\end{array}$} \\
\hline & Day cases & $1-3$ & $4-7$ & $\geqslant 8$ & Average & \\
\hline Gynaecological surgery & 0 & 72 & 4 & 28 & $4 \cdot 3$ & 104 \\
\hline Genitourinary surgery & 125 & 61 & 2 & 40 & $2 \cdot 9$ & 228 \\
\hline General surgery & 90 & 41 & 76 & 11 & $3 \cdot 0$ & 218 \\
\hline Orthopaedic surgery & 45 & 39 & 0 & 8 & $2 \cdot 2$ & 92 \\
\hline Ear, nose, and throat surgery & 65 & 122 & 248 & 17 & $3 \cdot 8$ & 452 \\
\hline
\end{tabular}

TABLE III-Patients on "deferred" waiting list

\begin{tabular}{lcc}
\hline \multicolumn{1}{c}{ Specialty } & $\begin{array}{c}\text { No of patients } \\
\text { awaiting } \\
\text { admission }\end{array}$ & $\begin{array}{c}\text { Patients on } \\
\text { "deferred" } \\
\text { waiting list }\end{array}$ \\
\hline General surgery & 218 & 46 \\
Genitourinary surgery & 228 & 163 \\
Ear, nose and throat surgery & 452 & 0 \\
Orthopaedic surgery & 92 & 0 \\
Gynaecological surgery & 104 & 0 \\
\hline
\end{tabular}

otolaryngology all 452 patients were included on the "officiat waiting list," but in genitourinary surgery 163 of $228(71 \%)$ wers excluded from the DHSS's list because they were waiting for revie procedures. Yet all represented future planned work for the hospitå and all needed a surgical procedure in the operating theatre. Most of these were day cases requiring a cystoscopy check for review of bladder tumour.

In the second part of the study the 448 patients who were actuall $\$$ admitted under the care of one general surgeon (PAS) in the three month period were reviewed. Of these, 299 patients $(67 \%)$ wer admitted from the waiting list, 117 being day cases. One hundre and forty nine patients (33\%) were either emergency admissions of. urgent transfers from other wards in the hospital, and of these jusf 
seven were day cases. The elective admissions accounted for 882 inpatient days and the emergency admissions 1008 inpatient days. The average length of stay of an elective admission was 2.9 days, compared with 6.8 days for emergency admissions. Although $67 \%$ of patients were admitted electively, they accounted for only $47 \%$ of the bed day occupation that resulted from the admissions.

\section{Discussion}

Patients may be admitted to a surgical bed, either as a planned or as an emergency admission, as a result of a consultation that may take place in many locations, including the outpatient clinic, accident and emergency unit or a medical ward, the general practitioner's surgery, the patient's home, or a consultant's private rooms. The admission may be immediate or deferred and if deferred this may be for many reasons, including lack of medical urgency, lack of bed availability, or a delay for medical or social reasons. The possible routes to a surgical bed are outlined in the figure. The

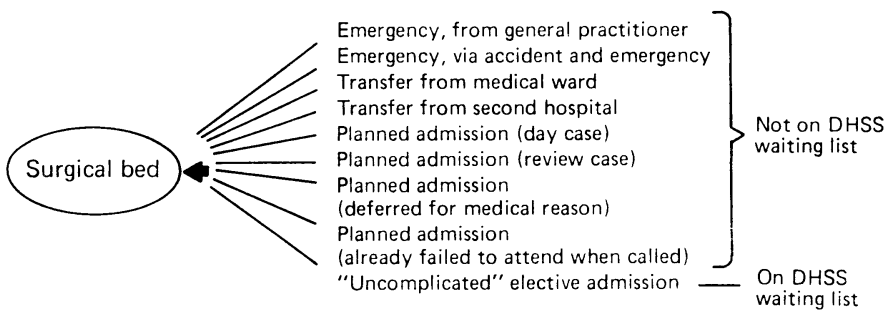

Possible routes to a surgical bed.

official DHSS waiting list figures include only a proportion of the total number of surgical admissions; patients requiring checks or reviews, day cases, as well as patients deferred for medical, social, or personal reasons are not included.

An analysis of the waiting list for an entire district general hospital at a specific time produces several interesting facts. The longer an individual patient has been waiting the more likely it is that he will have declined one or more opportunities to be admitted so that after two years $96 \%$ of patients will have already had a chance to enter hospital. Most of these patients were never admitted as they ultimately proved to have left the area or to have had their operations at another hospital or had decided not to proceed to surgery. It is now our hospital policy to write to patients who do not attend for admission asking whether they still wish their name to remain on the waiting list.

In this study $67 \%$ of patients were "non-urgent admissions," but this accounts for only a minority of hospital work (47\%) as judged by the periods in hospital which actually resulted from these admissions in the practice of one surgeon when studied over a three month period. This is because patients admitted as an emergency had a longer mean length of inpatient stay $(6.8$ days) than patients admitted electively ( $2 \cdot 9$ days). Most general surgical beds were filled with patients whose admission had been prompted by an accident or medical emergency, leaving a minority of beds at any one time available for planned surgical procedures.

\section{MISLEADING METHOD}

The presentation of official DHSS waiting list statistics is misleading in several respects. The official list omits various groups of patients who are waiting to come into hospital. It omits day cases, thus excluding 325 of 1094 patients awaiting surgery in this study; it omits 314 patients who have defaulted when called for admission; and it omits 209 patients awaiting check or review procedures. Some individual patients are excluded from the official waiting list figures because they fall under more than one of the exclusion criteria; 608 patients awaiting planned admission to the hospital were on the official DHSS waiting list but 486 were excluded. Thus the total of planned surgical admissions is $79 \cdot 9 \%$ greater than the DHSS figures suggest.

These omissions mean that comparisons between specialties are misleading. For example, a comparison of the DHSS waiting list in gynaecology and in genitourinary surgery in this study showed 104 gynaecology patients awaiting admission compared with 103 in genitourinary surgery, suggesting similar waiting times. In fact an extra 125 day cases were also awaiting admission in urology, all needing to go to theatre. Similarly, the omission of "review" patients from official statistics eliminated 163 (of 228) urology patients, but no ear, nose and throat or gynaecological patients were eliminated.

Since the official DHSS waiting list records only the number of patients awaiting admission in each specialty and does not record the expected time in hospital for each, the waiting list for gynaecology (104 patients) seems similar to that in orthopaedic surgery ( 92 patients). The estimated average length of admission for a gynaecological patient, however, is $4 \cdot 3$ days, which is almost double that for an orthopaedic patient $(2 \cdot 2$ days). A better indication of the waiting list would be the expected number of bed days required to clear the list.

This study suggests that the official DHSS waiting list statistics would be improved by the inclusion of categories of patients at present excluded, though it is acknowledged that this would not alter the time that an individual patient waited for elective admission.

There are obviously many factors influencing the number of patients on a waiting list, which represents the balance of patients added to the list as well as patients removed from it. ${ }^{3}$ These include not only the factors discussed above but also the number of new patients seen by each surgeon in a week and the proportion of these patients who are accepted on to the waiting list as well as the number of patients who bypass the list by being accepted for immediate admission. Also important are the number of patients removed from the waiting list. Again this will vary with many factors including availability of staff, beds, theatres, and equipment, to which must be added personal factors about the surgeon, such as his age, experience, working practices, organisation, and enthusiasm. These are factors that are easily overlooked yet are probably as important as more easily measured variants.

\section{Conclusion}

The DHSS waiting list is a poor indication of the number of patients awaiting hospital admission. The true number of patients awaiting admission to the hospital is $79.9 \%$ greater than the official figure. The magnitude of this difference varies a great deal from one surgical specialty to another. The figures would be more meaningful if day cases and patients awaiting check or review procedures were included and if the expected duration of admission for patients was assessed.

I would like to thank Mrs J Burns and Mrs M Hollingworth for valuable secretarial help and $\mathrm{Mr}$ A Cawthron for encouragement and advice.

\section{References}

Department of Health and Social Security. Management services, annual hospital statistical return SH3. London: DHSS, 1979. (HN(79)99.)

2 Morris D. Surgical waiting lists. Br Med f 1984;289:271-2

3 White A. Waiting lists. Hospital and Health Services Review 1980;76:270-4. 